\title{
PRIZE ESSAY
}

\section{oN \\ J O H N H O A R D}

AS $\mathbf{\Lambda}$

PSYCHOLOGICAL STUDY.

A Prize of $£ 10$ is offered by Professor GoY, of King's College, London, for the best essay on the above subject. The essay, besides containing an analysis of the character of John Howard, and the circumstances, physical and moral, under which it developed itself, must treat of the relation of the conduct of Howard during the infancy, childhood, and early manhood of his son, to the son's lapse into the state of mind in which he died. The prize is not to be awarded to any essay which the judges shall not deem of sufficient merit. The essays to bear a motto, and the same motto to be written on assealed envelope containing the author's name and address. The envelope to be opened only in the case of the successful candidate.

The essays to be sent to Dr. Maddslex, 9, Hanover Square, London, on or before June 1st, 1874. 